九州大学学術情報リポジトリ

Kyushu University Institutional Repository

\title{
Exploring Attitudes and Household Culture to Encourage Water Conservation Behavior
}

Singha, Bipasha

Water and Environmental Engineering Laboratory, IGSES, Kyushu University

El jamal, Osama

Water and Environmental Engineering Laboratory, IGSES, Kyushu University

https://doi.org/10.5109/4738581

出版情報: Proceedings of International Exchange and Innovation Conference on Engineering \& Sciences (IEICES). 7, pp. 149-154, 2021-10-21. 九州大学大学院総合理工学府 バージョン:

権利関係: 


\title{
Exploring Attitudes and Household Culture to Encourage Water Conservation Behavior
}

\author{
Bipasha Singha ${ }^{1,2,3}$ and Osama Eljamal ${ }^{1,2 *}$ \\ ${ }^{1}$ Water and Environmental Engineering Laboratory, IGSES, Kyushu University, Japan \\ ${ }^{2}$ Department of Earth System Science and Technology, Kyushu University, Japan \\ ${ }^{3}$ Department of Psychology, University of Dhaka, Dhaka-1000, Bangladesh \\ ${ }^{*}$ Corresponding author email: osama-eljamal@kyudai.jp
}

\begin{abstract}
Water is a valuable natural resource for all living species to sustain a productive ecosystem. The goal of this study was to determine the primary variables of home water use to target those elements in water demand control efforts. We designed three questionnaires relating to attitude, culture, and behavior for this purpose, all of which were reliable and valid to a satisfactory level. Using a survey of 210 university students and employees across the Fukuoka city, Japan, we found that attitude and culture play an important role in determining water conservation behavior. Households who reported a stronger culture and positive attitude of water conservation used less water. We also discovered that among various age groups and gender categories, there was a substantial difference in favorable attitude, culture, and behavior about water conservation. Person's attitude, culture, and gender account for $29 \%$ of overall variation in water conservation. Thus, good water-saving attitude and culture are linked to water conservation behavior, underline the importance of policies that encourage long-term social changes in how people consider about the water use.
\end{abstract}

Keywords: attitude, behavior, culture, water conservation

\section{INTRODUCTION}

Water is one of life's most basic need, as it has a significant impact on community health and living requirements. Only about 3\% of the world's water resources are useful. There are currently water shortages in many areas, with over a billion individuals without access to safe drinking water. This issue is one of the most critical signs of why we must be extremely cautious and aware of our water uses [1-3]. Global freshwater demand has been quickly increasing as human populations and economies have grown. Global population growth, climate change, and lifestyle changes are placing expanding pressure on our crucial freshwater resources, resulting in significant water shortages in many nations $[4,5]$.

Therefore, the urgent necessity to conserve and preserve natural resources is becoming increasingly apparent [6]. Water supplies will be put under even more strain soon, and policymakers will have to strike a balance between meeting rising demand for water and ensuring the longterm viability of ecosystems. Hence, household water demand management has become a priority for preserving precious water resources [7,8]. Water demand management aims to encourage homeowners to voluntarily conserve water by using water-efficient equipment or changing their water-use habits [9].

Water conservation in the residential home mainly entails actions that reduce water consumption. Overconsumption is a major contributor to worldwide environmental change. Economic motivations (e.g., water price), technical upgrades (e.g., water-saving household appliances), policy instruments and supervision, or behavior modification can all help to boost domestic water savings [10-13].

Water for Domestic Use in Japan

Domestic water use in Japan has increased by more than three times due to population growth and the expansion of economic activity. Baths (about 24 percent), toilets (approximately 28 percent), and laundry (approximately 28 percent) consume a considerable part of household water (approx. 17 percent).

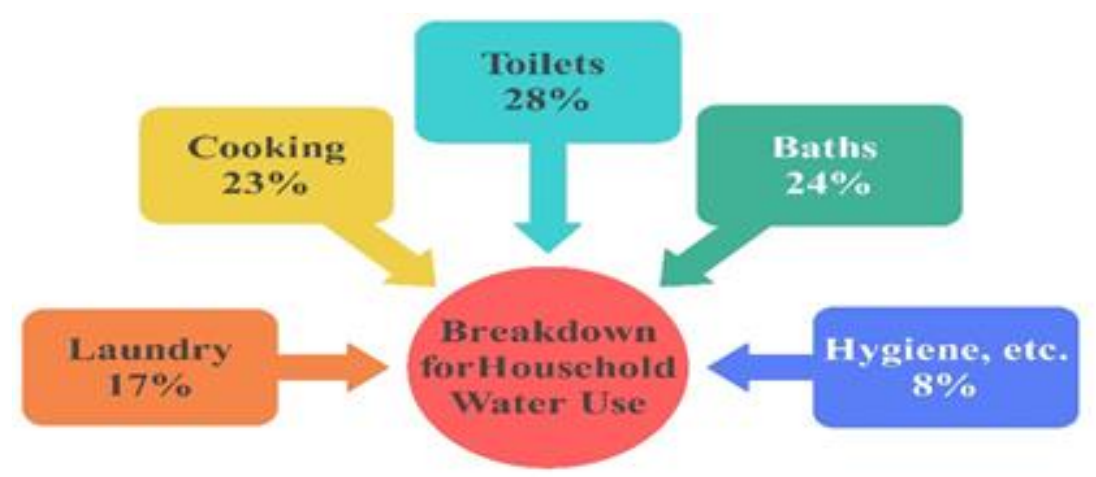

Figure 1: Data from the Bureau of Waterworks, Tokyo Metropolitan Government. 
Several researchers have attempted to understand the underlying processes that shape human behavior from the perspective of behavioral psychology over the years. Theory of planned behavior (TPB) is a well-established and widely used socio-psychological method for explaining and understanding individual behavior, particularly pro-environmental conduct $[14,15]$. The essential variable, according to TPB, is attitude, which refers to a person's favorable/unfavorable and/or positive/negative assessment of executing a behavior [14] or the measure of an individual's support or non-support of a given activity [16,17]. Previous studies [1820]found that households with more positive attitudes to water conservation used less water. TPB also showed that individuals' aspirations to conserve water are stronger when they receive social support from important persons. Water use in the house is a collective behavior that involves the actions of several household members. Unless other members of the home share that commitment, a single person's commitment to water conservation is unlikely to result in reduced household water use. As a result, household dynamics may play a significant role in residential water consumption. From these perspectives, the present research measures sociodemographic variables and psychosocial variables (Attitude and culture) as determinants of water conservation behaviors.

\section{METHODS}

\subsection{Sample and data collection}

The final sample size of the present study was 210 university students and employees living in Japan (121 male and 89 female) and their age ranged from 18-45 years. An internet-based questionnaire was devised considering the COVID-19 epidemic and the risk that people's willingness to complete a paper-based questionnaire might be reduced. We used e-mails as well as the most prominent social media platforms, such as Facebook, WhatsApp, and LinkedIn. Everyone who completed our assessment was encouraged to forward the link to their peers. To be eligible for inclusion, respondents had to be international students, be able to give informed consent online, and be 18 years old or older at the time of data collection. Respondents were requested to provide their informed consent via an online preamble before beginning the questionnaire. The data were obtained from January to April 2021.

\subsection{Measures}

Multiple-item measures were used to assess all research variables (attitude, culture, and behavior). All the items were derived following a thorough evaluation of previously published research and tailored to the needs of the current study. A panel of specialists with extensive knowledge in environmental psychology and water science assessed the content validity of the research tool in terms of relevancy and precision of items, as well as the robustness of the questionnaire. The final questionnaire comprised of 15 approved items assessed on a five-point Likert response scale after a few adjustments ranging from " $1=$ strongly disagree" to " $5=$ strongly agree".

\subsection{Data analysis methods}

The collected data were analyzed by using Item analysis, Pearson Product moment correlation, Confirmatory factor analysis, t-test, one way ANOVA, and multiple regression.

\section{RESULTS}

To ensure the reliability of the scales (Attitude, Culture, and Behavior), item analysis was conducted. Moreover, confirmatory factor analysis was performed to make sure the validity of each scale. Pearson product moment correlation indicated the correlation among attitude, culture, and behavior scales. t-test was applied to measure the gender differences and One way ANOVA for age difference (Four age categories: 18-24, 25-31, 32$38,39-45)$.

Table 1: Results of Pearson correlation test, item analysis and Average variance explained.

\begin{tabular}{|lllll|}
\hline Construct & Attitude & Culture & Behavior \\
\hline Attitude & 1 & & \\
Culture & $.24^{* *}$ & 1 & \\
Behavior & $.43^{* *}$ & $.38^{* *}$ & 1 \\
Cronbach's alpha & .78 & .79 & .83 \\
AVE & .55 & .64 & .54 \\
\hline
\end{tabular}

The results indicated that Cronbach's alpha ranged from 0.78 to 0.83 , while AVE values ranged from 0.54 to 0.64 , all of which were greater than the required least threshold standards. As a result, the models were found to have convergent validity for the constructs. To evaluate the link between the constructs, the Pearson correlation test was used. All constructs had a significant correlation with each other, according to the results (given by the bolded items). 


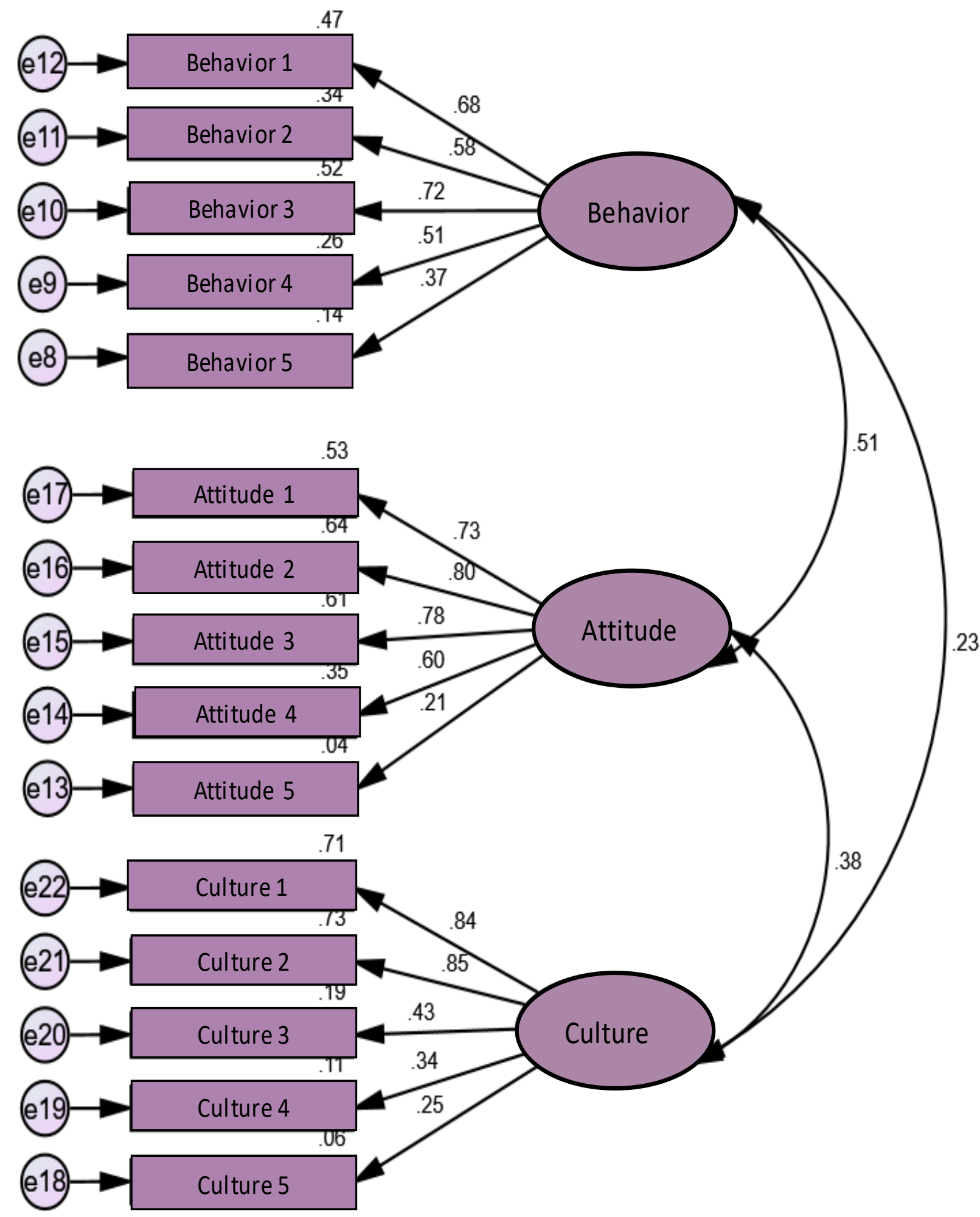

Figure 2: Standardized factor loading values

Confirmatory factor analysis was used to assess and show the models' validity (Figure 2). The findings of confirmatory factor analysis revealed that model goodness-of-fit indices were appropriate and satisfactory (the model fit indicators are mentioned below, respectively: $\chi 2 / \mathrm{df}=2.65,2.3, \mathrm{GFI}=0.90, \mathrm{NFI}=0.92$, $\mathrm{IFI}=0.96, \mathrm{CFI}=0.96, \mathrm{TLI}=0.95, \mathrm{RMSEA}=0.040)$. 
Table 2. Gender difference among attitude, culture, and behavior of university student in Japan.

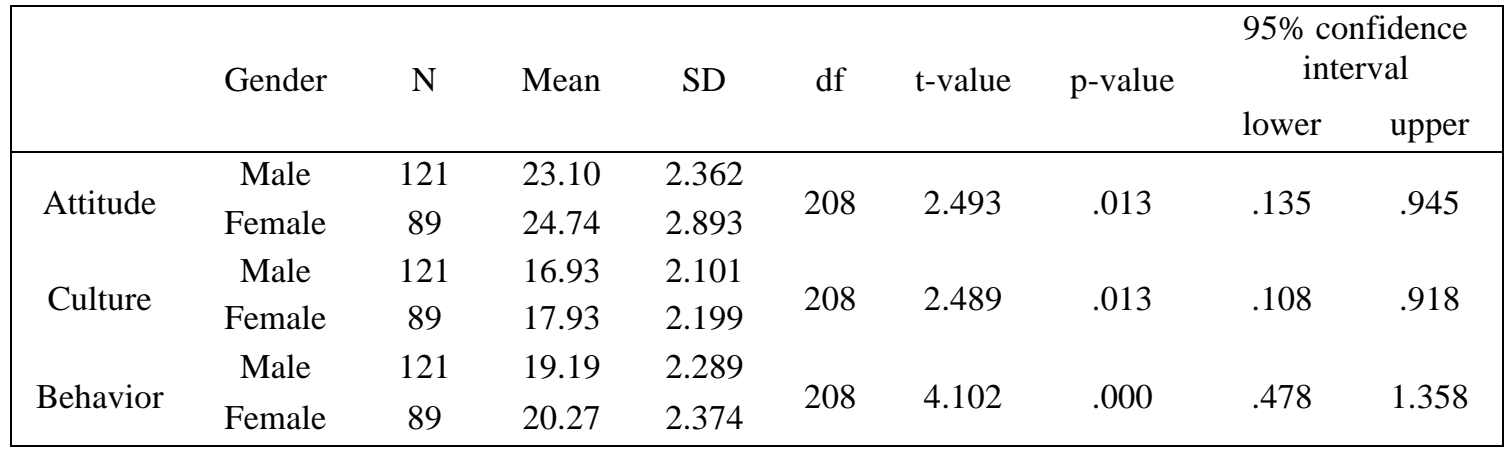

Significant at $* * \mathrm{p}<0.01$

The results obtained from t-test revealed that there was a significant difference among attitude, culture, and behavior according to gender. Female participants had more positive attitude and more water conservation culture. They were also more involved to conservation behavior than male participants

Table 3. Differences among attitude, culture, and behavior in terms of age using ANOVA technique.

\begin{tabular}{|cccccc|}
\hline Variables & Between MS & Within MS & df & F-value & p-value \\
\hline Attitude & 52.260 & 16.523 & 209 & 3.163 & .024 \\
Culture & 161.676 & 26.773 & 209 & 20.872 & .000 \\
Behavior & 68.185 & 5.517 & 209 & 12.360 & .000 \\
\hline
\end{tabular}

Significant at $* * p<0.01$

According to the findings of the ANOVA, there was a significant difference in positive attitude, culture, and behavior regarding water conservation among various age groups. For more specific results, Tukey HSD pairwise comparisons showed that participants aged above 31 had significantly more positive attitude, strong conservation culture and more engaged in conservation activities

Table 4. Effect of attitude and culture on behavior using multiple regression analysis.

\begin{tabular}{|ccccc|c|}
\hline Variables & Estimates & Std. error of & t-value & p-value & Adjusted R $^{2}$ \\
\hline Gender & 0.659 & 0.219 & 3.012 & 0.003 & \\
Attitude & 0.270 & 0.040 & 6.751 & 0.000 & 0.29 \\
Culture & 0.104 & 0.038 & 2.692 & 0.007 & \\
\hline
\end{tabular}

Significant at $* * \mathrm{p}<0.01$

Multiple regression was conducted to ascertain the effects of gender, attitude, and culture on water conservation behavior. Results suggested that attitude and culture have positive statistically significant effect on water conservation behavior. For instance, one unit increase of positive attitude and culture score, water conservation behavior upsurge on average 0.27 percent and 0.10 percent. Findings also reveal that female are more engage to water conservation than male. Moreover, $29 \%$ of the total variation of water conservation is explained by person attitude, culture, and gender.

\section{DISCUSSION AND CONCLUSION}

The purpose of this study was to determine the importance of demographic and psychosocial factors in household water saving. The findings showed that the three scales constructed in this study are practical and valuable tools for investigating attitudes, culture, and behavior, as well as strong correlations among them. According to the findings, water conservation attitudes have a substantial association with water conservation practices, which is consistent with earlier studies [21,22]. Accordingly, if people perceive that water conservation is a reasonable, essential, and useful deed that brings them pleasure and satisfaction, they are more likely to engage in relevant behaviors in their homes. Waterconserving families also had a water-conserving culture at home and hence practiced more water-conserving habits $[23,24]$. We also found that there was a significant difference in positive attitude, culture, and behavior regarding water conservation among various age groups and gender category. Female participants exhibited a more optimistic attitude and were more concerned about water conservation. They were also more concerned about environmental issues than male participants. 
Participants above the age of 31 had a more positive attitude, a stronger conservation culture, and were more involved in conservation efforts. Gregory and Di Leo [25] found that families with older occupants used less water, although there was a positive correlation between age and water use. Regression analysis discovered that the attitude, culture, and gender of individuals account for $29 \%$ of the overall variation in water conservation. To summarize, the current study found that demographic and psychosocial factors play a significant impact in predicting household water use. Managing water supplies in metropolitan areas is currently and, in the future, a serious concern for policymakers. The current study sheds light on the aspects that should be prioritized when attempting to manage home water consumption. This data can be used to guide future research into household water conservation measures.

\section{REFERENCES}

[1] Kılıç Z. The importance of water and conscious use of water. Int J Hydrol 2020;4:239-41. https://doi.org/10.15406/ijh.2020.04.00250.

[2] Postel SL. Entering an era of water scarcity: The challenges ahead. Ecol Appl 2000;10:941-8. https://doi.org/10.1890/10510761(2000)010[0941:EAEOWS]2.0.CO;2.

[3] Pahl-Wostl C. Transitions towards adaptive management of water facing climate and global change. Water Resour Manag 2007;21:49-62. https://doi.org/10.1007/s11269-006-9040-4.

[4] World Economic Forum. Global Risks Report 2019. 2019.

[5] Shahangian SA, Tabesh M, Yazdanpanah M. How can socio-psychological factors be related to water-efficiency intention and behaviors among Iranian residential water consumers? J Environ Manage $2021 ; 288$. https://doi.org/10.1016/j.jenvman.2021.112466.

[6] Saurí D. Water conservation: Theory and evidence in urban areas of the developed world. Annu Rev Environ Resour 2013;38:227-48. https://doi.org/10.1146/annurev-environ-013113142651.

[7] Darbandsari P, Kerachian R, Malakpour-Estalaki S. An Agent-based behavioral simulation model for residential water demand management: The case-study of Tehran, Iran. Simul Model Pract Theory 2017;78:51-72. https://doi.org/10.1016/j.simpat.2017.08.006.

[8] Marlow DR, Moglia M, Cook S, Beale DJ. Towards sustainable urban water management: A critical reassessment. Water Res 2013;47:7150 61. https://doi.org/10.1016/j.watres.2013.07.046.

[9] Lee M, Tansel B. Water conservation quantities vs customer opinion and satisfaction with water efficient appliances in Miami, Florida. J Environ Manage 2013;128:683-9. https://doi.org/10.1016/j.jenvman.2013.05.044.

[10] Singha B, Eljamal O. A Review on Water Conservation and Consumption Behavior: Leading Issues, Promoting Actions, and Managing the Policies. Proc Int Exch Innov Conf
Eng Sci 2020;6:171-8. https://doi.org/10.5109/4102484.

[11] Karmaker SC, Hosan S, Chapman AJ, Saha BB. The role of environmental taxes on technological innovation. Energy 2021;232:121052. https://doi.org/10.1016/j.energy.2021.121052.

[12] Shamal Chandra Karmaker, Md. Matiar Rahman, Hosan S, Bidyut Baran Saha. The Impact of Biomass Energy Consumption on Human Development: Evidence from Asian Countries. Proc Int Exch Innov Conf Eng Sci 2020;6:204-11. https://doi.org/10.5109/4102489.

[13] Karmaker SC, Hosan S, Saha BB. Does biomass energy consumption improve human development? Evidence from South Asian countries. Int Energy J 2021;21:81-92.

[14] Ajzen I. The theory of planned behavior. Organ Behav Hum Decis Process 1991;50:179-211. https://doi.org/10.1016/0749-5978(91)90020-T.

[15] Gao L, Wang S, Li J, Li H. Application of the extended theory of planned behavior to understand individual's energy saving behavior in workplaces. Resour Conserv Recycl 2017;127:107-13. https://doi.org/10.1016/j.resconrec.2017.08.030.

[16] Guo Z, Zhou K, Zhang C, Lu X, Chen W, Yang S. Residential electricity consumption behavior: Influencing factors, related theories and intervention strategies. Renew Sustain Energy Rev 2018;81:399-412. https://doi.org/10.1016/j.rser.2017.07.046.

[17] Fielding KS, Russell S, Spinks A, Mankad A. Determinants of household water conservation: The role of demographic, infrastructure, behavior, and psychosocial variables. Water Resour Res 2012;48. https://doi.org/10.1029/2012WR012398.

[18] Clark WA, Finley JC. Determinants of Water Conservation Intention in Blagoevgrad, Bulgaria. Soc Nat Resour 2007;20:613-27. https://doi.org/10.1080/08941920701216552.

[19] Lam SP. Predicting intentions to conserve water from the theory of planned behavior, perceived moral obligation, and perceived water right. J Appl Soc Psychol 1999;29:1058-71. https://doi.org/10.1111/j.1559-

1816.1999.tb00140.x.

[20] Lam SP. Predicting intention to save water: Theory of planned behavior, response efficacy, vulnerability, and perceived efficiency of alternative solutions. J Appl Soc Psychol 2006;36:2803-24. https://doi.org/10.1111/j.00219029.2006.00129.x.

[21] Yazdanpanah M, Hayati D, Hochrainer-Stigler S, Zamani GH. Understanding farmers' intention and behavior regarding water conservation in the Middle-East and North Africa: A case study in Iran. J Environ Manage 2014;135:63-72. https://doi.org/10.1016/j.jenvman.2014.01.016.

[22] Russell S V., Knoeri C. Exploring the psychosocial and behavioural determinants of household water conservation and intention. Int $\mathbf{J}$ Water Resour Dev 2020;36:940-55. https://doi.org/10.1080/07900627.2019.1638230.

[23] Ramsey E, Berglund EZ, Goyal R. The impact of demographic factors, beliefs, and social influences 
on residentialwater consumption and implications for non-price policies in urban India. Water (Switzerland) 2017;9:1-21. https://doi.org/10.3390/w9110844.

[24] Moglia M, Cook S, Tapsuwan S. Promoting water conservation: Where to from here? Water (Switzerland) 2018;10. https://doi.org/10.3390/w10111510.

[25] Gregory GD, Di Leo M. Repeated Behavior and Environmental Psychology: The Role of Personal Involvement and Habit Formation in Explaining Water Consumption. J Appl Soc Psychol 2003;33:1261-96. https://doi.org/10.1111/j.15591816.2003.tb01949.x. 